\title{
POESIA E JÚBILO EM HILDA HILST'
}

\section{POETRY AND JUBILATION IN HILDA HILST}

\author{
Alexandre de Melo Andrade²
}

RESUMO: Em Júbilo, Memória, Noviciado da paixão, Hilda Hilst provoca uma atmosfera poética caracterizada pela própria experiência poética, situando a figura do poeta na gestação da palavra, no êxtase da imaginação, numa constante espera de um outro, do encontro, mas que se alimenta mais da expectativa do que da presença física do ser amado. Nesse sentido, a relação estabelecida entre a poeta e o homem pode ser aproximada à relação da poesia com a divindade. A última parte da obra, intitulada "Poemas aos homens do nosso tempo", possibilita considerações sobre a sobrevivência da poesia num mundo mutilado pela necessidade de riqueza e poder. Pretendemos, então, tematizar essa oposição. Para tais discussões, traremos considerações de Staiger (1997), Bosi (2000), Pécora (2001), dentre outros.

PALAVRAS-CHAVE: Hilda Hilst. Poesia. Júbilo. Sagração.

ABSTRACT: In Júbilo, Memória, Noviciado da Paixão, Hilda Hilst provokes a poetic atmosphere characterized by her own poetic experience, placing the figure of the poet in the gestation of the word, in the ecstasy of the imagination, in a constant wait for another, for the encounter, but which is nourished more of expectation than of the physical presence of the loved one. In this sense, the relationship established between the poet and man can be approximated to the relationship between poetry and divinity. The last part of the work, entitled "Poemas aos homens do nosso tempo", allows for considerations about the survival of poetry in a world mutilated by the need for wealth and power. We intend, then, to focus on this opposition. For such discussions, we will bring considerations by Staiger (1997), Bosi (2000), Pécora (2001), among others.

KEYWORDS: Hilda Hilst. Poetry. Jubilation. Consecration.

\footnotetext{
${ }^{1}$ Artigo recebido em 12 de março e aceito em 12 de abril de 2021.

${ }^{2}$ Doutor em Estudos Literários. Professor Adjunto do Departamento de Letras Vernáculas, PPGL/ UFS e do PROFLETRAS/UFS. Membro dos grupos de pesquisa Poesia Brasileira Moderno-Contemporânea (UFG), Estudos em Leitura Literária (UFS) e Grupo de Estudos em Filosofia e Literatura (UFS). Email: alexandremelo06@uol.com.br. ORCID: https://orcid.org/0000-0002-8467-607X.
} 
Júbilo, Memória, Noviciado da Paixão, de Hilda Hilst, é publicado em 1974, pela Massao Ohno. Numa breve contextualização, é importante dizer que sua produção poética, a partir década de 70 , correu paralelamente à produção de prosa de ficção, tendo em vista que em 1970 e em 1973 a escritora já havia publicado as obras de ficção Fluxo-floema e Qadós, respectivamente. A poesia é o gênero que pratica por mais tempo; no entanto, vale dizer que Hilda Hilst é poeta até na prosa, o que é perceptivel no trabalho estético com a linguagem e a estruturação distante das convenções narrativas. Mesmo na chamada literatura pornográfica, ou pornô cult, que veio a desenvolver alguns anos mais tarde, os expedientes romanescos aparecem sob o signo da poesia.

O livro de poesias sobre o qual nos ocupamos aqui traz aspectos caros ao universo literário da poeta, como o constante diálogo com a tradição mítica da antiguidade clássica e com a tradição lírica medieval, a absorção de atmosferas místicas e a atenção ao próprio fazer poético, comumente visto pelo seu caráter de sagração, conforme será exposto nas leituras que faremos de alguns poemas.

Numa observação mais geral de Júbilo, Memória, Noviciado da Paixão, observamos uma divisão interna de sete partes, a saber: "Dez chamamentos ao amigo", "O poeta inventa viagem, retorno, e sofre de saudade", "Moderato cantabili", "Ode descontínua e remota para flauta e oboé. De Ariana para Dionísio", "Prelúdios-intensos para os desmemoriados de amor", "Árias pequenas. Para bandolim" e "Poemas aos homens do nosso tempo". Pelos títulos, é possível entrever o caráter mítico e metapoético a que aludimos no parágrafo anterior, além do cruzamento com elementos da música. A primeira parte já nos informa da atividade do poeta em sua capacidade de inventividade e de sofrimento, enquanto que a última provoca forte oposição entre o poeta e o projeto de civilização do qual ele também faz parte, embora de forma distanciada.

O título do livro aproxima termos que dão uma dimensão do fazer poético empreendido pela poeta, de modo que se torna pertinente uma explicação dos mesmos. Os dicionários, de um modo geral, designam "júbilo" como alegria excessiva, sensação de felicidade, entusiasmo. No texto bíblico, o termo é associado à alegria próxima da santidade, à adoração, à entrega aos bons 
sentimentos. No episódio do Ano do Jubileu, em Levítico 25: 8-22, Deus, em conversa com Moisés, associa o Ano do Jubileu ao ano da liberdade, de retorno à propriedade e à família, de bênção e amor ao próximo:

E declarareis santo o quinquagésimo ano, e proclamareis liberdade na terra e a todos os seus habitantes. Esse vos será um ano de jubileu, pois cada um de vós retornará à sua propriedade, e cada um à sua família.

Esse ano quinquagésimo será para vós jubileu; não semeareis, nem colhereis o que nele nascer por si mesmo, nem colhereis nele as uvas das vides não tratadas, porque é jubileu; será santo para vós; comereis o que brotar nos campos.

Nesse ano do jubileu, cada um retornará à sua propriedade. (2008, p. 138).

Ao anunciar o "júbilo", Hilda Hilst certamente ressignifica a atmosfera poética criada pelo poeta, aproximando-a do episódio bíblico.

O segundo termo aludido no título também sobrepuja o traço semântico da religiosidade. Segundo o Dicio, "Noviciado" significa "Tempo de provação a que estão sujeitos os noviços, antes dos votos". A poeta se insere, como pode ser claramente visto nos primeiros poemas, no tempo da espera pelo outro, e que realiza sua poesia justamente no período de ausência. Assim, a poesia surge, durante o "noviciado da paixão", como atividade empreendida na solidão, na espera, na incompletude.

Evocando, ainda no título, a "memória", a poeta parece atualizar o status da lírica, considerada o canto de (re)invocação do tempo, do passado, de chamamento das mesmas vozes que cantaram a/na ausência, o que é projetado, principalmente, nas mitologias aludidas em vários poemas. Podemos, ainda, interpretar a relação entre lírica e memória em âmbito maior, entendendo o lirismo em seu sentido de resgate do passado, de reinserção nas formas essenciais, primordiais. Neste sentido, a própria linguagem da lírica seria fonte de revisitação do passado, e a criação lírica seria um canto que, ressoando as lembranças, instituiria sempre o novo. 
Émil Staiger, em Conceitos fundamentais da poética, aproxima lirismo e recordação. Segundo o teórico, "O poeta lírico escuta sempre de novo em seu íntimo os acordes já uma vez entoados, recria-os, como os cria também no leitor" (1997, p. 28). Na lírica, repete-se o que está no passado. O stimmung - termo inglês utilizado por Staiger para referir-se à disposição interna do poeta no ato da criação -, ressoa sempre, e de novo, num movimento circular, que também remete a Octavio Paz, quando diz que a poesia é um "Convite à viagem; retorno à terra natal. [...] Arte de falar de uma forma superior; linguagem primitiva. [...] Retorno à infância, coito, nostalgia do paraíso, do inferno, do limbo. [...] o poema é um caracol onde ressoa a música do mundo." (2012, p. 21).

Dadas as explicações, é possível compreender que Júbilo, Memória, Noviciado da Paixão projeta uma atmosfera religiosa na produção lírica. Resguardadas as diferenças discurso religioso e lirismo, o ofício do poeta cumpre uma destinação que o aproxima da contemplação, da solidão e da entrega ao divino, conforme se verá pelas leituras aqui sugeridas. Tomemos, a princípio, o poema VI da primeira parte:

Sorrio quando penso

Em que lugar da sala

Guardarás o meu verso.

Distanciado

Dos teus livros políticos?

Na primeira gaveta

Mais próxima à janela?

Tu sorris quando lês

Ou te cansas de ver

Tamanha perdição

Amorável centelha

No meu rosto maduro?

E te pareço bela

Ou apenas te pareço

Mais poeta talvez

E menos séria?

O que pensa o homem?

Do poeta? Que não há verdade

Na minha embriaguez

E que me preferes

Amiga mais pacífica

E menos aventura? 


\author{
Que é de todo impossível \\ Guardar na tua sala \\ Vestígio passional \\ Da minha linguagem? \\ Eu te pareço louca? \\ Eu te pareço pura? \\ Eu te pareço moça? \\ Ou é mesmo verdade \\ Que nunca me soubeste? \\ (2001, p. 22-23).
}

Os dez poemas que compõem esta primeira parte têm como aspecto central a referência direta ao amado, que desperta na mulher/poeta um diálogo consigo mesma. Há uma forte tensão entre ela, que fica entregue aos transes da imaginação poética, e ele, homem do mundo, aderente às necessidades e imposições sociais, cumprindo deveres, situado numa esfera distante do fazer-poético. A poesia, neste caso, surge na incompletude, na espera; assim, o espaço da casa pode ser visto como contraponto ao espaço do mundo.

O homem político, representado pelo ausente, pode ser compreendido como homem social e, portanto, distante da criação poética. Desse modo, há certa incompreensão do homem em relação à poeta, sendo aquela que justamente subverte a conduta coletiva, o que pode ser manifestado não apenas nos modos como é vista pelos outros ("perdição", "embriaguez", "aventura", "louca"), mas também pela sua própria linguagem, que é de "vestígio passional". O espaço ocupado por ela enquanto poeta a distancia dos códigos sociais vigentes.

Com isso, podemos inferir que a obra sobre a qual falamos aqui institui uma relação tensa entre o eu e o outro, repercutindo na discussão acerca do espaço da poesia no mundo. A ideia do poeta como sujeito marginal foi muito explorada no Romantismo, que compreendia a poesia, teoricamente, como circunscrita no universo da analogia, em contraposição à concretude do mundo. Compreendemos que "A analogia, muito discutida pelos teóricos do Romantismo, resulta dessa natureza animada que corresponde a um estado interior e espiritual maior que a realidade visível. Trata-se, aqui, do poeta mago, que decifra os mistérios da natureza e afina-se a ela metafórica e sinestesicamente." (ANDRADE, 
2017, p. 61). A analogia situa a poesia numa esfera circular, mítica, distante do que Hilst pontua como o homem político, imerso na linearidade das convenções e da realidade tangível.

O poema é todo marcado pelos pontos de interrogação, sinalizando o interlocutor - o homem político -, a quem a poeta se dirige pensando como sua natureza poética é vista por ele. A última estrofe, marcada por apenas dois versos, sugere que é possível haver, na verdade, um desconhecimento dessa sua natureza, o que indicaria uma distância ainda maior entre ela e homem, entre o poeta e o mundo.

Essa oposição de que tratamos aparece metaforizada, ao longo da obra, nos elementos terra e água, sendo a terra representada pela mulher/poeta, e a água representada pelo homem. De um lado, a fixidez; de outro, a fluidez. Na terceira estrofe do primeiro poema dessa parte, a poeta assim se refere a esta relação:

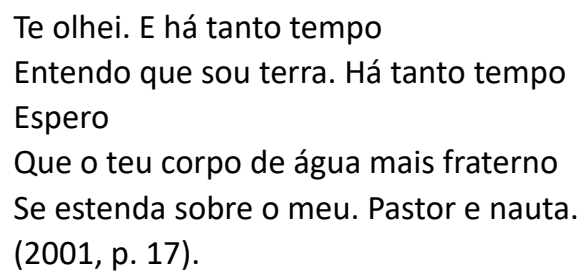

A poeta, que está na espera, permanece num espaço fixo (terra). O homem, na sua inconstância e na sua entrega ao mundo, é sempre movimento (água). A terra é firme, segura, mas é fértil: faz nascer, brotar, dá a vida. Em A poética do devaneio, Bachelard diz que " $A$ atmosfera inteira é, numa respiração cósmica, respirada pela terra" (2006, p. 172); a terra contém tudo o que suporta, mantendo relação cósmica com tudo o que nasce dela. Em outra passagem, o teórico afirma: "[...] como a Terra é 'viva', segue-se que, como todos os seres vivos, ela respira. Ela respira, como o homem respira, expelindo para longe de si o seu hálito." (2006, p. 173; aspas do autor). Em consonância com tal simbologia, a terra corresponde, nas filosofias orientais, à abundância e à criatividade, sendo, ainda, a grande mãe que acolhe e abriga. Em Júbilo, Memória, Noviciado da Paixão, a terra é o elemento diretamente associado à mulher, aquela que espera pelo acolhimento do amado, porém, fazendo com que a vida nunca cesse, produzindo-a liricamente. 
Por outro lado, o homem político, o amado, é o avesso da contemplação, estando entregue ao fluxo ininterrupto do mundo. Sendo aquoso, no sentido da movimentação e da inconstância, o homem justamente perde a vida.

No prefácio da edição utilizada aqui, Alcir Pécora alude a essa relação entre terra e água de que estamos tratando, afirmando que "o lugar da tese é ocupado pela devoção da persona lírica, definida como amante arrebatada, que deseja ter junto de si, todo o tempo, o amado que Ihe falta, causando-Ihe dor e pena infinitas; a antítese se dá pela definição do amado esquivo e indiferente, cujas águas não chegam a tocar as margens [...]" (2001, p. 12-13; grifos do autor). A poética hilstiana se dá, aqui, por disjunção, sinalizando a possibilidade de criação na ausência mesma do outro.

Passemos ao poema VII, também da primeira parte:



O paradoxo "desamar, amando", exposto na penúltima estrofe, atravessa a obra, ratificando o que dissemos acima a respeito da cisão entre a poeta e o amado e o amor que se dá na ausência. Trata-se, aqui, da experiência órfica do poeta, que canta a não-realização do seu intento amoroso. A título de melhor esclarecimento, estamos aludindo ao mito grego de Orfeu, que narra a descida do personagem ao Hades para resgatar sua ama- 
da, Eurídice, habitante da morada dos mortos. Tendo seu desejo consentido, ele deveria voltar ao mundo dos vivos sem olhar para ela, que o seguia a certa distância; porém, Orfeu descumpre essa regra e, ao olhar para trás, perde sua Eurídice para sempre. É possível compreendermos o personagem como a representação do poeta, que canta na ausência, na incompletude. Orfeu, tendo perdido sua amada, utiliza a lira para expressar suas emoções, seduzindo, com sua música, até mesmo os animais mais selvagens.

O poema fica marcado pela falta ("noites que não foram tuas", "Intocado meu rosto-pensamento", "Intocado meu corpo", "à procura do teu corpo") e pelas oposições ("desamar, amando", "te lembrando [...] que eu te esqueça"). A poesia nasce do desejo e da falta, do pensamento e da imaginação. O verso nasce da espera do outro, numa constante preparação do que virá, ainda que a poeta saiba da impossibilidade da plenitude amorosa.

Há inúmeras referências, nos poemas, a Túlio. Assim, vale a pena fazer os devidos esclarecimentos. Túlio Hostílio (710 a.C 642 a.C) foi um guerreiro romano que se dedicou tanto às guerras que acabou não tendo tempo para os deuses; por isso, segundo conta a tradição, foi abatido por uma peste, como se fosse um castigo divino. O poema XIII, da segunda parte, refere-se ao personagem histórico da seguinte forma:

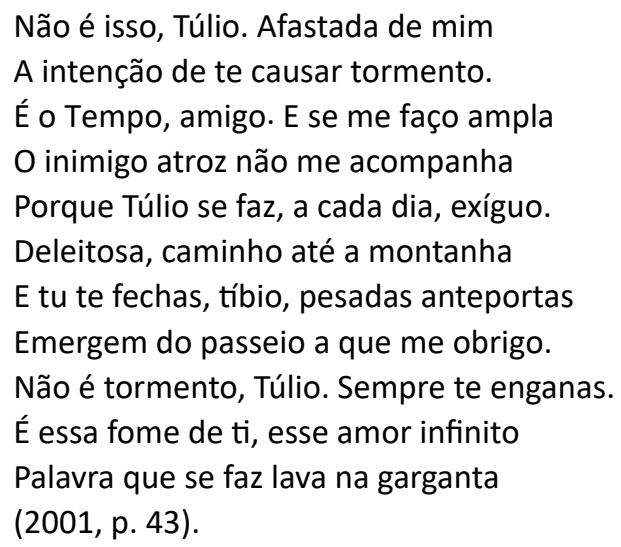

O poema faz uma aproximação entre o desejo de encontrar Túlio e o desejo pelo amor divino, expresso no amor infinito. Se Túlio é representado, de forma lendária, pelo afastamento da contemplação e de Deus, então a poeta é projeção, em alguma medida, do próprio sagrado: ainda que almejando estar com o 
amado, ele se afasta e se perde pelo mundo. Nesse sentido, o ser-poeta e o fazer-poético têm em comum com a divindade a sempre espera do outro, o olhar contemplativo, o amor que não cessa, a terra firme de onde nasce a própria criação. A poeta se vê na condição de quem ama e espera, mas é também representação da divindade que espera a devoção dos homens.

Ao pensar a relação entre mística e poesia em Hilda Hilst, Jonas Miguel Pires Samudio diz que "Na poesia hilstiana, não há pacificação, fim da luta entre os amantes; há, antes, uma intensificação da distância, do desejo que se reforça como impossibilidade e, além disso, desejo de impossibilidade [...]" (2013, p. 27), e que

[...] a poeta parece viver em conflito contínuo entre o convívio com o divino e com o humano; sua experiência, deste modo, passa a ser vivida intensamente no texto poético, mas com o dado sensível de quem experimenta o gozo e o aniquilamento no erotismo criatural e, ainda que consciente dos prodígios da alma, sabe que Deus é o conhecedor daquilo que criou na bondade original. (2013, p. 28).

No poema anterior (o de $\mathrm{n}$. XII), a poeta assim diz:

\author{
Túlio viaja. A sós. E o tempo passa. \\ Túlio nos ares, asa, e amplidão, \\ E o poeta morrendo, a sós, na casa, \\ O coração nos ares \\ (2001, p. 42).
}

Há sempre a referência ao tempo, que desarma as ilusões e sinaliza para a solidão da poeta. Túlio está em constante movimento, pervagando pelo mundo, e a poeta permanece na sua casa, como terra, fazendo poesia de seus desejos e de seus devaneios ("O coração nos ares").

A poeta vê-se como noviça da paixão, conforme aludido no título do livro, aproximando a experiência de espera pelo encontro com Deus à experiência da poeta em sua constante espera pelo outro, mas sendo ela mesma matizada pela sagração e o poder da criação lírica. Deus se manifesta na impossibilidade da presença; a criação lírica se manifesta na vivência do desejo, não da realização. O lugar da poesia, em Hilda Hilst, é "fundado 
no desejo do amado que falta, atinge ou atende ao apelo do ser essencial por meio da descoberta de um movimento ao mesmo tempo íntimo, rítmico e metafísico que se dá no âmbito da palavra" (PÉCORA, 2001, p. 13).

Na última parte da obra - "Poemas aos homens do nosso tempo" - a poeta se dirige a um interlocutor mais plural, ratificando, nos dezessete poemas, o papel da poesia e do poeta, que, mesmo à margem dos movimentos do mundo, têm a capacidade de repensar o mundo e de manter segura a própria condição humana, seus desejos e seus sonhos. Ao dizer, no poema de abertura desta seção, que "A ideia é ambiciosa e santa. / E o amor dos poetas pelos homens / É mais vasto / Do que a voracidade que vos move." (p. 106), a poeta novamente aproxima o fazer-poético do estado de sagração, de forma que sua santidade e seu amor pela humanidade transcenda a ambição cega e automatizada dos homens.

Vejamos o poema III dessa terceira parte:

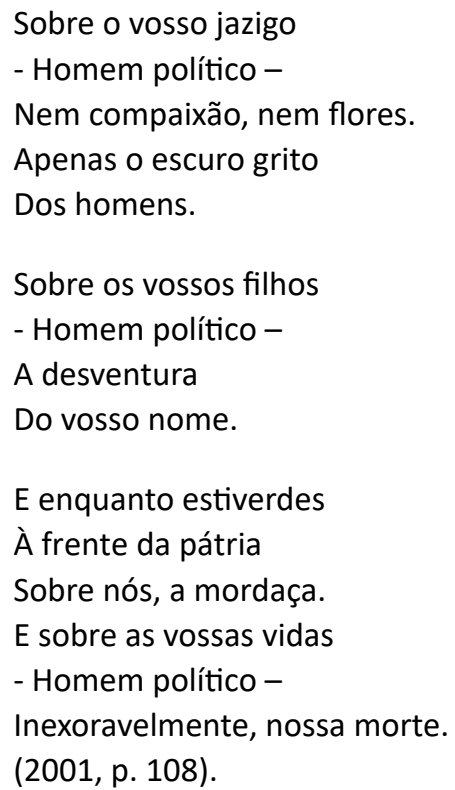

O poema apresenta um paralelismo entre os versos "Sobre o vosso jazigo", "Sobre os vossos filhos", "Sobre nós" e "sobre as vossas vidas", indiciando, para além da sonoridade, um diálogo entre o eu-lírico e o "homem político" (repetido três vezes), maldizendo-o e culpabilizando-o pela "mordaça" e pela "morte" que assola as pessoas. Aqueles que governam a pátria são desprovi- 
dos da sensibilidade inerente ao poeta, provocando a ruína de um mundo que também se perde com ele. Importa dizer que nestes poemas, o homem político, a princípio associado aos governantes das nações, atinge uma amplitude que sugere os homens de um modo geral, corruptos e entregues ao desgaste das atividades ininterruptas e, por isso, indiferentes à poesia. Desse modo, a poeta reitera a oposição estabelecida ao longo da obra, conforme expusemos no início do texto; há uma oposição de base entre vida e morte, estando a vida com os poetas e os deuses, e a morte com os homens, que viram as costas ao sagrado, permanecendo atados às esferas do social e da administração. O mundo torna-se lugar de prisão, enquanto que a casa é lugar de liberdade e de criação.

Júbilo, Memória, Noviciado da Paixão sugere que a poesia resiste à banalidade do mundo. Não por acaso, na última parte da obra, a poeta utilize um vocabulário mais agressivo, de execração dos homens, afastados, assim como o guerreiro Túlio, de Deus e do poeta.

No conhecido texto "Poesia-Resistência", Alfredo Bosi tangencia a poesia moderno-contemporânea, expondo seus modos de resistir às ideologias capitalistas. Segundo o crítico,

A poesia resiste à falsa ordem, que é, a rigor, barbárie e caos [...]. resiste ao contínuo "harmonioso" pelo descontínuo gritante; resiste ao descontínuo gritante pelo contínuo harmonioso. Resiste aferrando-se à memória viva do passado; e resiste imaginando uma nova ordem que se recorta no horizonte da utopia. (2000, p. 169; aspas do autor).

Em consonância com tal argumento, a poesia hilstiana estabelece diálogo com a tradição mítica e lírica, reelaborando os dramas dos personagens míticos e tocando aspectos da lírica antiga e medieval, garantindo a sobrevivência justamente das grandes marcas da poesia. Nesse sentido, a poeta tende a um fazer-poético de veio matalinguístico que, ainda de acordo com Bosi, é sintoma do tempo atual: "A poesia, reprimida, enxotada, avulsa de qualquer contexto, fecha-se em um autismo altivo; e só pensa em si, e fala dos seus códigos mais secretos e expõe a nu o esqueleto a que a reduziram; enlouquecida, faz de Narciso seu último deus" (2000, p. 166). 
Vale lembrar que esses expedientes de remitização e de diálogo com a tradição são constantes na lírica contemporânea, como é notável em poetas brasileiros como Ivan Junqueira, Orides Fontela, Alexei Bueno, Dora Ferreira da Silva, Geraldo Carneiro, dentre tantos outros. O crítico polonês Czeslaw Milosz, percebendo esse traço da arte contemporânea, diz que "A humanidade cada vez mais haverá de alimentar-se de si própria, cada vez mais haverá de contemplar o seu passado inteiro, procurando ali a chave para o enigma que ela é e penetrando, por empatia, a alma das gerações e civilizações que se foram" (2012, p. 146). Em decorrência disso, "Está mais viva do que nunca, outrossim, a presença de figuras míticas colhidas da literatura europeia ou de lendas literárias [...]" (2012, p. 147).

Hilda Hilst incorpora na alma do povo a alma do poeta, de forma que os mesmos anseios e sonhos do poeta estejam presentes na coletividade. Dirigindo-se ao homem político, que está em "cima do palanque / de cima da alta poltrona estofada / de cima da rampa", a poeta diz:

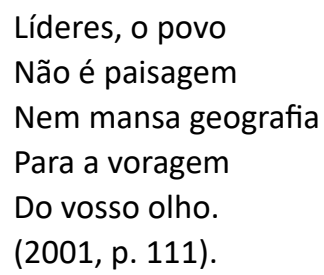

Assim, a poeta torna uníssona a sua voz e a voz do povo, circunscrevendo nelas o mesmo destino espiritual, que é o de resistir aos desmandos dos homens de poder e caminhar em direção aos sonhos e à utopia.

Essa última parte da obra possui aspecto dialético, pois o eu-lírico constantemente estabelece um diálogo com um interlocutor, ora visto como "homem político", ora como "líderes", como "tu", como "homem do nosso tempo" etc. Dessa disjunção entre a poeta e o interlocutor nasce a tensão de base da obra, de onde deriva a rejeição ao mundo e a apologia à atividade poética.

$\mathrm{O}$ poema VI dessa última parte atesta a supremacia da poesia sobre a arrogância e a mesquinhez do homem político: 
Tudo vive em mim. Tudo se entranha Na minha tumultuada vida. E porisso Não te enganas, homem, meu irmão, Quando dizes na noite, que só a mim me vejo. Vendo-me a mim, a ti. E a esses que passam Nas manhãs, carregados de medo, de pobreza, O olhar aguado, todos eles em mim, Porque o poeta é irmão do escondido das gentes Descobre além da aparência, é antes de tudo LIVRE, e porisso conhece. Quando o poeta fala Fala do seu quarto, não fala do palanque, Não está no comício, não deseja riqueza Não barganha, sabe que o ouro é sangue Tem os olhos no espírito do homem. Sabe de cada um A própria fome. Olha-me. Enquanto vive um poeta O homem está vivo.

(2001, p. 113).

Emblemático no conjunto da obra, o poema eleva o poeta à figura do visionário, que detém os segredos da experiência humana, que é livre e não se curva ao materialismo e à efemeridade das coisas. Nessa perspectiva, o poeta é irmão de todos os homens ("Vendo-me a mim, a ti") e sua comunicação se dirige ao espírito. Os dois versos finais provocam um fecho de ouro, fazendo um apelo ao homem/irmão para que descubra a importância da poesia/do poeta para a compreensão e a destinação humana.

O diálogo instituído pela poeta aqui e na obra de um modo geral projeta certo prosaísmo; a leitura dos versos faz entrever o uso constante do enjambement, além de toda uma rede sintática que propicia a interlocução e a fluidez da linguagem.

Abrindo o seu "noviciado" com os chamamentos ao amigo, a poeta passa pela própria reflexão poética, entendida como canto de espera, mas não de uma espera inerte, mas propiciadora da criação lírica, da reinvenção, do entendimento e manifestação dos sonhos e da imaginação. A poeta aproxima, assim, a espera do poeta pelo amado e a espera do noviço por Deus, ambos fazendo da distância o motivo maior da própria semeadura. 


\section{Referências}

ANDRADE, A. de M. A divinização da natureza em Novalis. Travessias Interativas. São Cristóvão, UFS, v. 13 , n 07, p. 58-67, 2017

BACHELARD, G. A Poética do Devaneio. Trad. Antonio de Pádua Danesi. São Paulo: Martins Fontes, 2006.

BÍBLIA SAGRADA. São Paulo: Vida Nova, 2008.

BOSI, A. Poesia-Resistência. In: BOSI, A. O ser e o tempo da poesia. São Paulo: Companhia das Letras, 2000.

HILST, H. Júbilo, Memória, Noviciado da Paixão. São Paulo: Globo, 2001.

HOLANDA, A. B. de. Dicio: Dicionário Online de Português. Disponível em: dicio.com.br. Acesso em 01 mar. 2021.

MILOSZ, C. O testemunho da poesia: seis conferências sobre as aflições do nosso século. Trad. Marcelo Paiva de Souza. Curitiba: Ed. UFPR, 2012.

PAZ, O. O Arco e a Lira. Trad. Ari Roitman e Paulina Wacht. São Paulo: Cosac Naify, 2012.

PÉCORA, A. Notas do organizador. In: HILST, H. Júbilo, Memória, Noviciado da Paixão. São Paulo: Globo, 2001.

SAMUDIO, J. M. P. Mística e poesia, nos limites da linguagem: Hilda Hilst e as místicas. Travessias Interativas, São Cristóvão, UFS, n. 5, p. 11-31, 2013.

STAIGER, Émil. Conceitos Fundamentais da Poética. Trad. Celeste Aída Galeão. Rio de Janeiro: Edições Tempo Brasileiro, 1997. 